\title{
Is Nottingham prognostic index useful after induction chemotherapy in operable breast cancer?
}

\author{
P Chollet ${ }^{1,2}$, S Amat ${ }^{*, 1,2}$, E Belembaogo ${ }^{3}$, H Curé ${ }^{1,2}$, M de Latour', J Dauplat', G Le Bouëdec', \\ M-A Mouret-Reynier', J-P Ferrière ${ }^{1,2}$ and $F$ Penault-Llorca ${ }^{1,2}$ \\ 'Centre Jean Perrin, 58 Rue Montalembert, BP 392, 6301 I Clermont-Ferrand Cedex I, France; ${ }^{2}$ INSERM U484, Rue Montalembert, \\ 63005 Clermont-Ferrand Cedex, France; ${ }^{3}$ Centre Hospitalier, BP 275, Libreville, Gabon
}

\begin{abstract}
The Nottingham prognostic index (NPI), based on tumour size in breast, node involvement and Scarff-Bloom-Richardson (SBR) grading, has been shown to constitute a definitive prognostic factor of primary operable breast cancer in the adjuvant setting. We performed a retrospective study to evaluate the prognostic value of this index in 163 patients after neoadjuvant chemotherapy. Secondly, we examined the influence on survival of a revised NPI, only based on residual tumour size in breast and SBR grading in 228 patients, and consequently called breast grading index (BGl). The prognostic value of these two indices was also evaluated by replacing the SBR grade with the MSBR grade, a French modified SBR grading; the modified NPI (MNPI) and modified BGI (MBGI) were, respectively, obtained in 153 and 222 patients. At a median follow-up of 9.3 years, survival was significantly related to these four indices $(P<0.001)$. Multivariate analysis revealed that $M B G I$ was the only one which retained a prognostic influence on disease-free survival $(P<0.02)$. In conclusion, the 'amount' of residual tumour in breast and/or nodes, as defined by NPI and revised indices, confers a determinant prognosis after neoadjuvant chemotherapy, inviting an alternative postsurgical treatment for a subgroup of patients with a decreased survival.
\end{abstract}

British Journal of Cancer (2003) 89, I |85- I |9|. doi:|0.1038/sj.bjc.660 I 258 www.bjcancer.com

(c) 2003 Cancer Research UK

Keywords: Nottingham prognostic index; neoadjuvant chemotherapy; residual disease; breast cancer

Selection of systemic adjuvant therapy is based on prognostic and predictive factors; prognostic factors are measurements associated with clinical outcome, whereas predictive factors are measurements related with the degree of response to a specific therapy (Adjuvant Therapy for Breast Cancer, 2000). Studies of prognostic factors in breast cancer to provide information on the risk of systemic recurrence and/or death after definitive primary therapy, and predictive factors help to choose which therapy might be particularly advantageous for the survival.

Many variables have been shown to correlate with prognosis of patients with breast carcinoma; among the most useful are the presence and number of axillary lymph-node metastasis, tumour size and histological grade (Adjuvant Therapy for Breast Cancer, 2000). However, these classical factors have been described after primary surgery and much less is known after primary chemotherapy followed by surgery. The National Surgical Adjuvant Breast and Bowel Project (NSABP) B-18 trial showed that neoadjuvant chemotherapy resulted in high rates of breast tumour response, axillary nodal downstaging and increased rates of breast preservation (Fisher et al, 1998). Moreover, some changes in biological markers have been shown that may be related to tumour response (Makris et al, 1999). Consequently, primary chemotherapy could possibly modify the prognostic value of known

\footnotetext{
*Correspondence: Dr S Amat, Centre Jean Perrin, Bureau de Recherche Clinique, 58 rue Montalembert, BP 392, 630 II Clermont-Ferrand Cedex I, France; E-mail: Recherche.Clinique@cjp.u-clermont I.fr Received 20 November 2002; revised I5 May 2003; accepted I5 July 2003
}

parameters. We have recently demonstrated that a complete pathological response conferred a survival advantage in patients with operable breast cancer after neoadjuvant chemotherapy (Chollet et al, 2002); a decreased survival was associated with an increasing number of nodes in these patients (Cure et al, 2002). Finally, we showed that primary chemotherapy seemed to induce some modifications in the Scarff-Bloom-Richardson (SBR) grading and, subsequently, only postchemotherapy SBR grading was an independent prognostic factor, whereas prechemotherapy SBR grade could predict the response to neoadjuvant chemotherapy (Amat et al, 2002).

In the present study, we examined the prognostic value of residual tumour, assessed by tumour size, SBR grade and lymphnode stage, after induction chemotherapy. The team of Nottingham City Hospital constructed a prognostic index based on these three parameters in patients with primary operable breast cancer (Haybittle et al, 1982). This index was subsequently validated and called the Nottingham prognostic index (NPI) (Galea et al, 1992). The NPI was used to define three subsets of patients with different chances of dying from breast cancer. As opposed to the British study, the Danish group used conventional axillary lymph-node staging and SBR grade evaluated only in ductal carcinomas (Balslev et al, 1994). Paradoxical data have been published concerning the prognostic significance of the NPI ever since (Sauerbrei et al, 1997; Sundquist et al, 1999; D'Eredita et al, 2001; Malmstrom et al, 2001; Fredriksson et al, 2002). Moreover, the NPI has not been evaluated in a neoadjuvant setting and, as for the SBR grade, we could wonder if it retains its prognostic value after primary chemotherapy. 
The purpose of this study was to apply the NPI to the characteristics of residual tumour after primary treatment in patients with operable breast cancer. Four indices have been calculated, corresponding to the sum of the individual scores concerning (i) tumour size, lymph-node status and SBR grade (NPI); (ii) tumour size and SBR grade (that we called the Breast grading index, BGI); (iii) tumour size, lymph-node status and MSBR grade (modified NPI, MNPI) and (iv) tumour size and MSBR grade (Modified BGI, MBGI).

\section{PATIENTS AND METHODS}

\section{Patients and treatment modalities}

Between 1982 and 2001, 451 patients were treated by six cycles at 21to 28-day intervals of neoadjuvant chemotherapy into five prospective phase II trials (Table 1), previously published (Belembaogo et al, 1992; Chollet et al, 1997, 2000; Van Praagh et al, 2001, 2002). The tumour size was $30 \mathrm{~mm}$ in diameter or more, or was situated in the central area of the nipple; all patients presented with stage II-III operable breast cancer, according to the International Union Against Cancer (UICC) recommendations (Sobin and Wittekind, 1997). The diagnosis was usually established by fineneedle aspiration or percutaneous microbiopsy of the primary tumour and clinically involved axillary lymph nodes. The local evaluation comprised clinical and echographic measurements of the tumour and nodes, a bilateral mammography, a breast MRI in some cases, and was repeated every two or three cycles of chemotherapy.

In all, 55 patients did not undergo surgery: $42 \mathrm{AVCF} / \mathrm{M}$ treated by radiotherapy alone, three acute allergies to taxotere, six progressions, two surgery refusals after clinical complete response and two too early. Then, 396 patients were operated after six cycles of treatment, by conservative surgery for good responders ( $n=280,70.7 \%)$ and modified radical mastectomy (MRM) for nonresponders $(n=116,29.3 \%)$ (Table 2$)$. Locoregional radiotherapy was instituted within 6 weeks in 422 patients, and additional courses of adjuvant chemotherapy were administered to 100 patients with significant residual disease. Finally, 200 menopausal patients with hormonal receptor-positive tumours received tamoxifen for 5 years.

Each patient was entered prospectively into the database and was observed longitudinally. The complete medical records of all patients were available for review at the time of this analysis.

\section{Evaluation of the NPI and revised NPI (BGI)}

The NPI was based on tumour size, lymph-node status and histological grade (Balslev et al, 1994), as follows: NPI $=0.2 \times$ tumour size $(\mathrm{cm})+$ lymph-node stage (1, node-negative; $2,1-3$ positive lymph nodes; $3, \geqslant 4$ positive lymph nodes) + SBR grade (1, good; 2 , moderate; 3 , poor).

These three parameters were evaluated in 163 out of the 451 patients, on needle core biopsies prospectively obtained when possible, from residual tumour at surgery after primary chemotherapy.

In order to identify a prognostic index, independent of axillary nodes involvement, we constructed another score, by excluding the parameter of lymph-node stage; it was called breast grading index (BGI), and was determined in 228 patients as $\mathrm{BGI}=0.2 \times$ tumour size $(\mathrm{cm})+$ SBR grade (1, good; 2 , moderate, 3 , poor).

\section{Evaluation of the two modified scores from NPI and BGI (MNPI and MBGI)}

The prognostic value of the NPI was also evaluated according to the modified SBR (MSBR) grading, obtained by ignoring the degree of differentiation, as previously described (Le Doussal et al, 1989). The MNPI was obtained in 153 patients, as follows:
Table I Dosing for the five regimens used in phase II trials

\begin{tabular}{|c|c|c|c|}
\hline Protocol & Tre & tment & \\
\hline $\begin{array}{l}\text { Every } 4 \text { weeks } \\
\text { AVCF/M } \\
\text { ( } n=164 \text { patients) }\end{array}$ & $\begin{array}{l}\text { Doxorubicin } \\
\text { Vincristine } \\
\text { Cyclophosphamide } \\
\text { Fluorouracil } \\
\text { When methotrexate } \\
\text { is added }\end{array}$ & $\begin{array}{l}\text { D1 } \\
\text { D1 } \\
\text { D2-D5 } \\
\text { D2-D5 } \\
\text { D2 and D4 }\end{array}$ & $\begin{array}{l}30 \mathrm{mg} / \mathrm{m}^{2} \\
1 \mathrm{mg} / \mathrm{m}^{2} \\
300 \mathrm{mg} / \mathrm{m}^{2} \\
400 \mathrm{mg} / \mathrm{m}^{2} \\
20 \mathrm{mg} / \mathrm{m}^{2}\end{array}$ \\
\hline $\begin{array}{l}\text { Every } 4 \text { weeks } \\
\text { NEM } \\
(n=112 \text { patients })\end{array}$ & $\begin{array}{l}\text { Vinorelbine/Navelbine }{ }^{\mathbb{R}} \\
\text { Epirubicin } \\
\text { Methotrexate }\end{array}$ & $\begin{array}{l}\mathrm{DI} \text { and D8 } \\
\mathrm{DI} \text { and D8 } \\
\mathrm{DI} \text { and D8 }\end{array}$ & $\begin{array}{l}25 \mathrm{mg} / \mathrm{m}^{2} \\
35 \mathrm{mg} / \mathrm{m}^{2} \\
20 \mathrm{mg} / \mathrm{m}^{2}\end{array}$ \\
\hline $\begin{array}{l}\text { Every } 3 \text { weeks } \\
\text { Taxotere } \\
(n=86 \text { patients })\end{array}$ & Docetaxel/Taxotere ${ }^{\mathbb{R}}$ & & $100 \mathrm{mg} / \mathrm{m}^{2}$ \\
\hline $\begin{array}{l}\text { Every } 3 \text { weeks } \\
\text { TNCF } \\
(n=69 \text { patients })\end{array}$ & $\begin{array}{l}\text { Theprubicin/THP- } \\
\text { adriamycin }^{\mathbb{R}} \\
\text { Vinorelbine/ Navelbine }{ }^{(\mathbb{R}} \\
\text { Cyclophosphamide } \\
\text { Fluorouracil }\end{array}$ & $\begin{array}{l}\mathrm{DI}-\mathrm{D} 3 \\
\mathrm{DI} \text { and D4 } \\
\mathrm{DI}-\mathrm{D} 4 \\
\mathrm{DI}-\mathrm{D} 4\end{array}$ & $\begin{array}{l}20 \mathrm{mg} / \mathrm{m}^{2} \\
25 \mathrm{mg} / \mathrm{m}^{2} \\
300 \mathrm{mg} / \mathrm{m}^{2} \\
400 \mathrm{mg} / \mathrm{m}^{2}\end{array}$ \\
\hline $\begin{array}{l}\text { Every } 3 \text { weeks } \\
\text { NET } \\
(n=20 \text { patients })\end{array}$ & $\begin{array}{l}\text { Vinorelbine/Navelbine }{ }^{\circledR} \\
\text { Epirubicin } \\
\text { Paclitaxel/Taxol }\left.\right|^{\circledR}\end{array}$ & $\begin{array}{l}\mathrm{DI} \text { and D8 } \\
\mathrm{DI} \text { and D8 } \\
\text { D9 }\end{array}$ & $\begin{array}{l}20 \mathrm{mg} / \mathrm{m}^{2} \\
35 \mathrm{mg} / \mathrm{m}^{2} \\
175 \mathrm{mg} / \mathrm{m}^{2}\end{array}$ \\
\hline
\end{tabular}

MNPI $=0.2 \times$ tumour size $(\mathrm{cm})+$ lymph-node stage $(1$, nodenegative; $2,1-3$ positive lymph nodes; $3, \geqslant 4$ positive lymph nodes) + MSBR grade $(1-5)$.

Similarly, MBGI was calculated in 222 patients, as follows: MBGI $=0.2 \times$ tumour size $(\mathrm{cm})+$ MSBR grade $(1-5)$.

\section{Follow-up and survival}

During the first 5 years of follow-up, patients had history and physical examination, complete blood count, liver function tests, serum CEA and CA 15-3 every 6 months. During the next 10 years, patients had these clinical examinations and biology every 6 months, and mammography performed at yearly intervals.

The overall survival (OS) and disease-free survival (DFS) were calculated from the date of diagnosis with the Kaplan-Meier method (Kaplan and Meier, 1958); the cutoff date was 15 October 2002. The survival was analysed as a function of prognostic indices. Three groups were defined for each index according to the distribution of patients, as shown in Table 3. The log-rank statistic test was used for univariate comparisons of survival end points (Mantel, 1966). A stepwise Cox's regression procedure (Cox, 1972) was used to classify the NPI, BGI and modified scores among main prognostic factors after neoadjuvant chemotherapy, that is, node involvement, residual tumour size, SBR and MSBR grades. A Pvalue of 0.05 or lower was considered statistically significant.

\section{RESULTS}

\section{Study population}

Table 2 lists the main characteristics of patients according to the four indices evaluated (NPI, BGI, MNPI and MBGI). No significant 
Table 2 Characteristics of patients treated by neoadjuvant chemotherapy in the overall population $(n=45 \mathrm{I})$, and in the population evaluated for NPI $(n=163), \mathrm{BGI}(n=228), \mathrm{MNPI}(n=153)$ and MBGI $(n=222)$

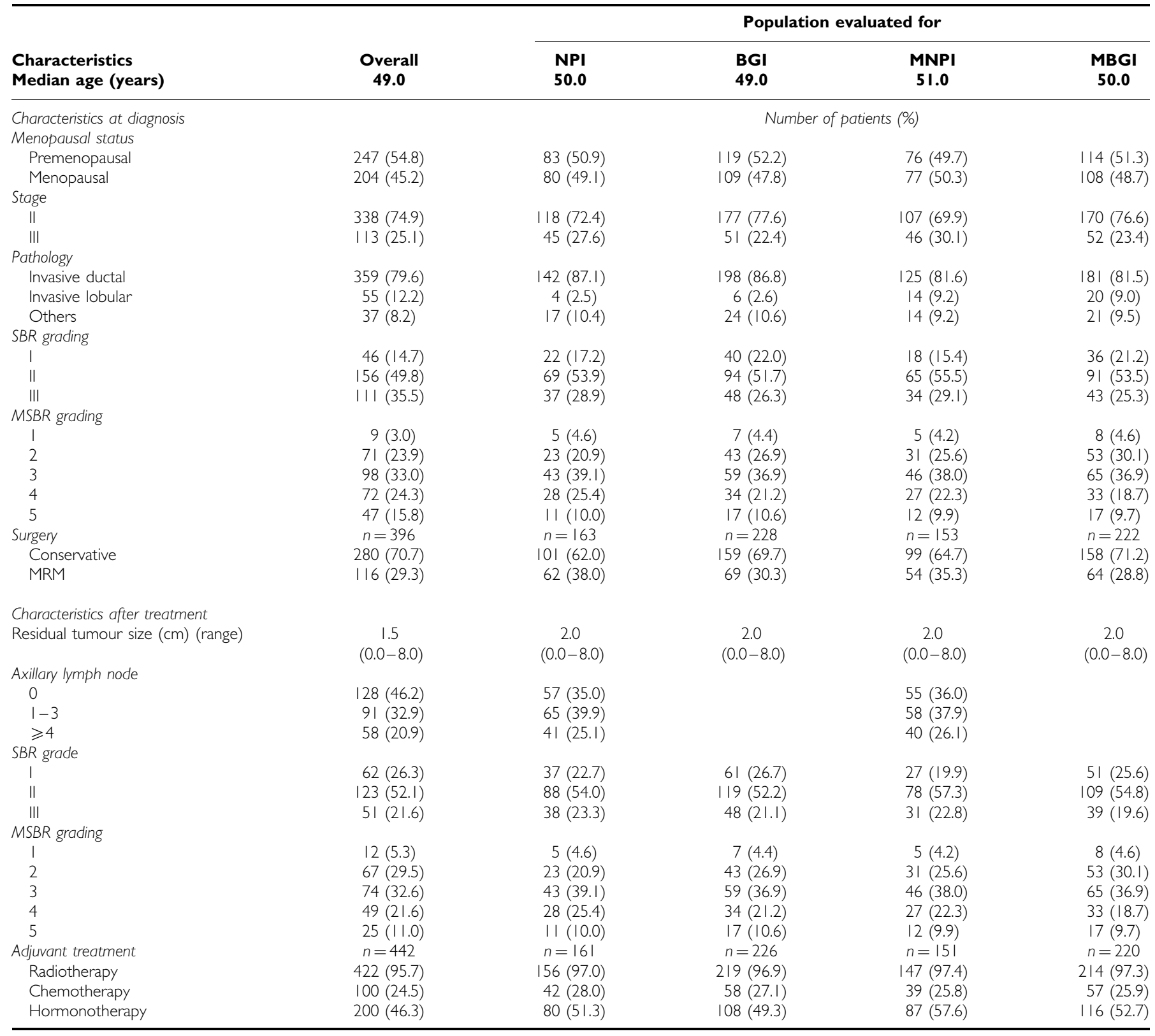

$\mathrm{SBR}=$ Scarff-Bloom-Richardson grading in patients with invasive ductal carcinoma; MSBR= modified SBR grading; MRM= modified radical mastectomy. In each group, the number of patients is not always equal to the total population due to the presence of certain nonmeasurable characteristics, withdrawal for drug allergies or toxicities. Moreover, 55 patients had not undergone surgery: 42 AVCF/M treated by radiotherapy alone, three acute allergies to taxotere, six progressions, two surgery refusals after clinical complete response, two too early.

difference was observed for patients and tumour characteristics between these four groups. The median age of overall population $(n=451)$ was 49 years $(25-80)$ and $54.8 \%$ of women were premenopausal. In all, $359(79.6 \%)$ patients presented with invasive ductal carcinoma. At diagnosis, there were 338 (74.9\%) stage II and $113(25.1 \%)$ stage III tumours, with a median tumour size of $4.0 \mathrm{~cm}(1.5-13.0)$. At surgery, the residual tumour size decreased to $1.5 \mathrm{~cm}(0.0-8.0)$. Of these, $128(46.2 \%)$ patients did not have involved axillary node [pN0] at surgery after initial chemotherapy; and $91(32.9 \%)$ patients had more than one and less than four positive nodes and 58 (20.9\%) had four or more nodes. After treatment, SBR grade divisions were $26.3 \%$ grade I ( $14.7 \%$ at diagnosis), $52.1 \%$ grade II ( $49.8 \%$ at diagnosis) and $21.6 \%$ grade III (35.5\% at diagnosis). The MSBR grade at surgery was 1 in 5.3\%, 2 in 29.5\%, 3 in $32.6 \%, 4$ in $21.6 \%$ and 5 in $11.0 \%$ of tumours, whereas there were $3.0 \%$ grade $1,23.9 \%$ grade 2 , $33.0 \%$ grade $3,24.3 \%$ grade 4 and $15.8 \%$ grade 5 tumours at diagnosis.

\section{Survival analysis}

Univariate analysis After a median follow-up of 9.3 years, OS and DFS were analysed as a function of NPI, BGI and modified scores after neoadjuvant chemotherapy. 
Table 3 Survival analysis as a function of NPI and BGI scores after induction chemotherapy

\begin{tabular}{|c|c|c|c|c|c|}
\hline & No. of patients (\%) & 10-year OS (\%) & $P$-value at 10 years & I0-year DFS (\%) & $P$-value at 10 years \\
\hline$[2.2-3.9]$ & $54(33.1)$ & 91.2 & & 65.3 & \\
\hline$[4.0-5.7]$ & 91 (55.8) & 55.5 & 0.0006 & 45.8 & 0.006 \\
\hline \multicolumn{6}{|l|}{$B G l$} \\
\hline$[1.0-2.1]$ & 65 (28.5) & 84.6 & & 63.0 & \\
\hline$[2.2-3.3]$ & $133(58.3)$ & 65.6 & 0.004 & 52.7 & 0.001 \\
\hline$[2.1-3.8]$ & $50(32.7)$ & 91.3 & & 60.1 & \\
\hline$[3.9-5.7]$ & 81 (52.9) & 56.7 & 0.0009 & 41.9 & 0.002 \\
\hline$[5.8-7.6]$ & $22(14.4)$ & 41.3 & & 16.7 & \\
\hline \multicolumn{6}{|l|}{$M B G I$} \\
\hline$[1.2-2.9]$ & $75(33.8)$ & 92.2 & & 67.6 & \\
\hline$[3.0-4.7]$ & $119(53.6)$ & 61.8 & 0.0002 & 44.2 & 0.0001 \\
\hline$[4.8-6.6]$ & $28(12.6)$ & 39.0 & & 25.6 & \\
\hline
\end{tabular}

$\mathrm{OS}=$ overall survival; $\mathrm{DFS}=$ disease-free survival.

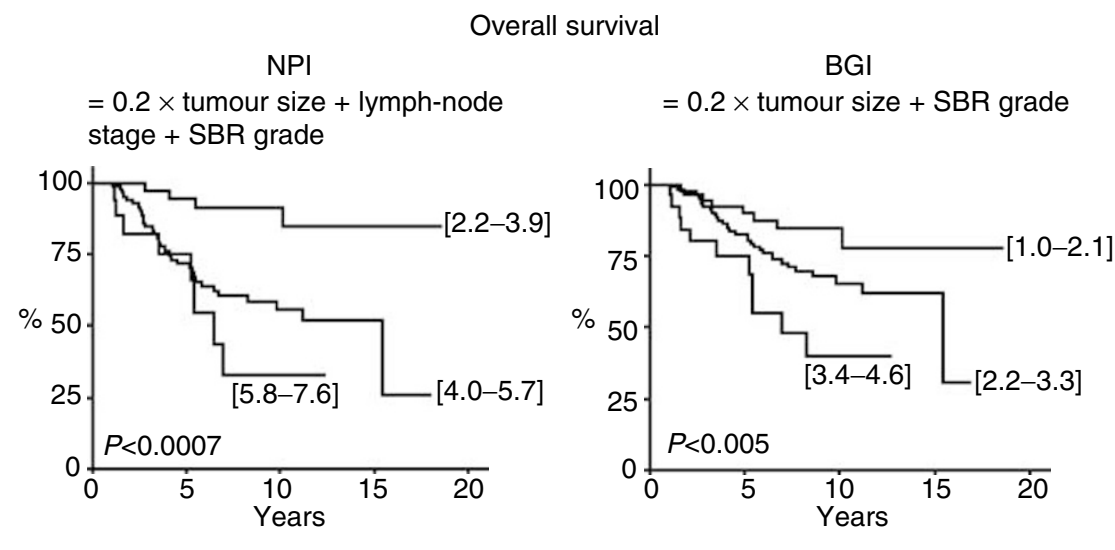

NPI

Disease-free survival
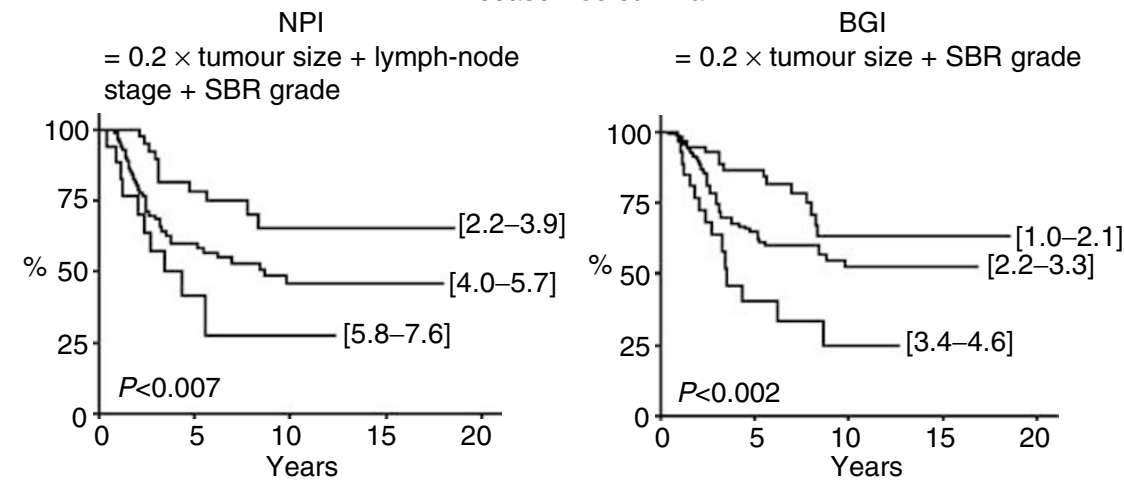

Figure I Univariate analysis of OS and DFS as a function of NPI based on SBR grading after neoadjuvant chemotherapy, with or without lymph-node stage.

As shown in Table 3, analysis of distribution showed that patients were divided into three groups for each NPI. The median values were $4.3(2.2-7.6)$ for NPI, $2.4(1.0-4.6)$ for BGI, $4.4(2.1$ 7.6) for MNPI and $3.4(1.2-6.6)$ for MBGI. As shown in Table 3 and Figure 1, univariate analysis showed that the two NPI scores evaluated according to SBR grade (NPI and BGI) were significantly related with OS and DFS $(P<0.001)$. Patients with an NPI $<4$ or a BGI $<2.2$ had a better prognosis than others, with a 10 -year OS of 91.2 and $84.6 \%$, and a 10 -year DFS of 65.3 and $63.0 \%$, respectively.
Similarly, MNPI and MBGI seemed to have a high prognostic influence on OS $(P<0.001$ and $P<0.0003$, respectively) and DFS $(P<0.003$ and $P<0.0002$, respectively). Two excellent prognostic groups were also underlined: subgroups with MNPI $<3.9$ and MBGI $<3$ (Table 3 and Figure 2).

Multivariate analysis Multivariate analysis did not reveal any prognostic factors of OS. Conversely, the MBGI appeared as the most significant prognostic factor of DFS $(P<0.02)$, with an eight- 
Overall survival

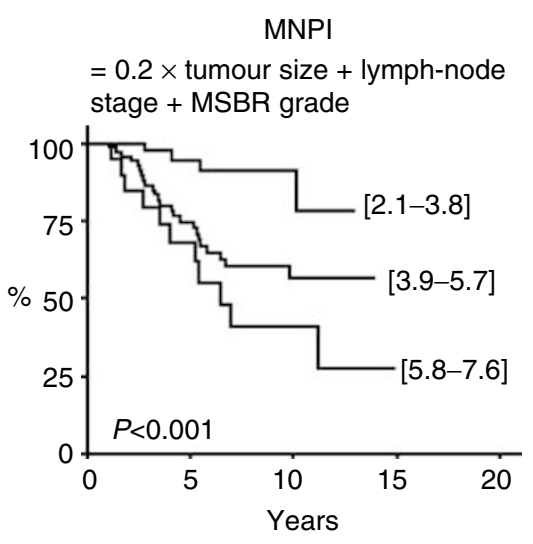

$$
=0.2 \times \text { tumour size }+ \text { MSBR grade }
$$

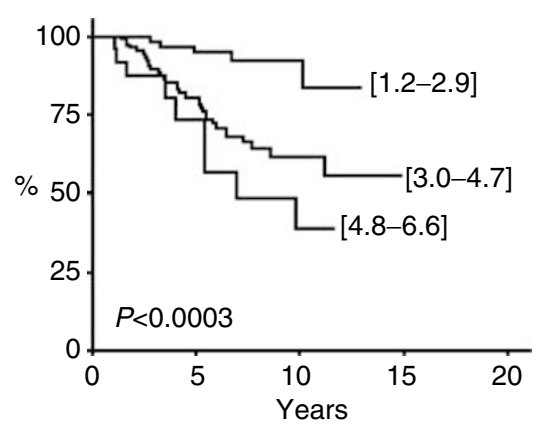

Disease-free survival

MNPI

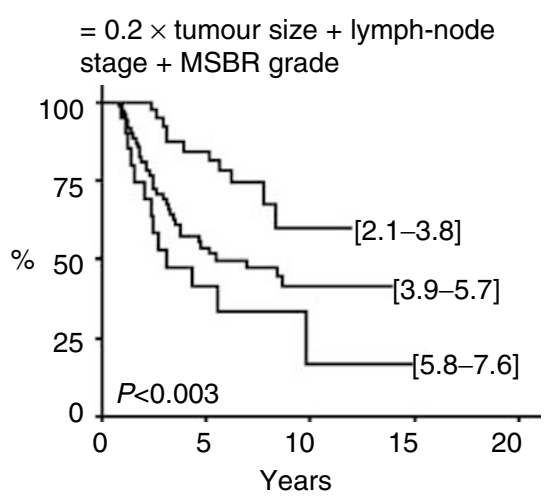

MBGI

$=0.2 \times$ tumour size + MSBR grade

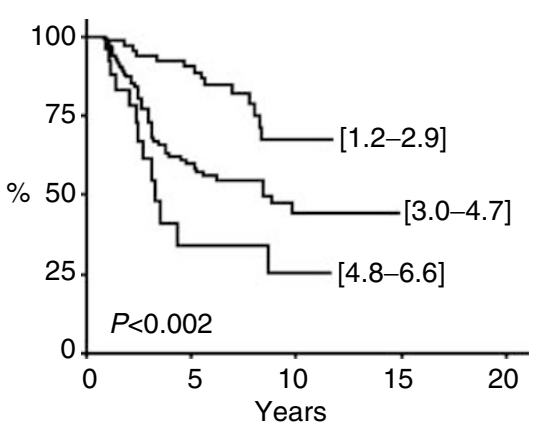

Figure 2 Univariate analysis of OS and DFS as a function of NPI based on MSBR grading after neoadjuvant chemotherapy, with or without lymph-node stage.

fold increased relative risk of death for patients with an MBGI ranging from 4.8 to 6.6. Node involvement after neoadjuvant chemotherapy was also correlated with DFS $(P<0.03)$. All other parameters considered, as SBR and MSBR grades, residual tumour size or other NPI scores did not have prognostic significance on DFS, probably due to the small number of patients in this multivariate analysis $(n=182)$.

\section{DISCUSSION}

Several prognostic factors have been identified in breast cancer. Among the most useful of these are the presence and number of axillary lymph-node metastasis, tumour size, histological type and SBR grade. The most powerful is indisputably the node involvement with a prognosis inversely related to the number of involved nodes, even after neoadjuvant chemotherapy and whatever the treatment administered (Cameron et al, 1997; Pierga et al, 2000; Cure et al, 2002). SBR grading is also by itself a prognostic parameter; survival was worse in patients with poorly differentiated tumours (grades II and III) compared with well-differentiated grade I tumours (Simpson et al, 2000; Latinovic et al, 2001; Amat et al, 2002). The tumour size in breast seems to be of lesser significance. All these parameters are available (i) on pathological examination at diagnosis; (ii) at surgery for the adjuvant setting; or (iii) on residual tumour after neoadjuvant chemotherapy followed by surgery.

Some studies showed the incidence and outcome of patients with a pathological complete response (pCR) after neoadjuvant chemotherapy (Machiavelli et al, 1998; Kuerer et al, 1999; Chollet et al, 2002). Conversely, what is the role of residual disease on survival in patients with operable breast cancer after neoadjuvant chemotherapy? And how to express this role? Our approach consisted of representing the 'amount' of residual disease by collecting the three recognised prognostic factors, that is, the node involvement, SBR grade and tumour size. This combination constitutes a score called NPI, a reference index of the literature (Haybittle et al, 1982; Galea et al, 1992; Balslev et al, 1994). Originally designed with a special three nodes dissection (Haybittle et al, 1982; Galea et al, 1992), it has been converted into more conventional axillary dissection by the Danish group (Balslev et al, 1992). In our study, we applied the NPI to patients with operable breast cancer treated by neoadjuvant chemotherapy, by incorporating or not the parameter of nodal involvement (NPI and BGI). Moreover, the prognostic value of these two indices was also evaluated by replacing the SBR grading with the MSBR grading (MNPI and MBGI). This French modification of the SBR grade retains five prognostic classes instead of three (Le Doussal et al, 1989); MSBR grade, based on nuclear pleomorphism and mitoses, can be determined in all tumours, independent of the histological type, whereas the SBR grade is only performed in invasive ductal carcinomas (Page, 1991; Charpin et al, 1995).

Our results showed that the NPI score fully retained its prognostic value after neoadjuvant chemotherapy, whatever the modalities of calculation $(P<0.001)$, that is, according to SBR grading or MSBR grading, with or without the parameter of nodal involvement. The division of prognostic groups, used in the 
Nottingham Study according to the NPI (i.e. good: NPI $\leqslant 3.4$; moderate: $3.4<\mathrm{NPI} \leqslant 5.4$; and poor: NPI $>5.4$ ), was modified in our study and realised according to the distribution of patients. However, if we consider the Nottingham subgroups, the 10-year survival rates are, respectively, $86.9,62.9$ and $40.5 \%$, with a $P$-value of 0.007 (data not shown). So, these value are nearly closed to those of the Danish group, who, respectively, obtained 10-year survival rates of $79.0,55.9$ and $24.7 \%$. The minor difference observed may be attributed to the benefit of adjuvant therapies, especially for the poor prognostic group. Multivariate analysis revealed that MBGI was the only one which retained a prognostic influence on DFS $(P<0.02)$. Its evaluation, based on tumour size and MSBR grading, offers the advantage of identifying patients with favourable prognosis, independent of the nodal involvement.

In conclusion, in addition to pCR, the residual tumour assessed by tumour size in the breast, SBR grading and nodal involvement combined in NPI had a highly prognostic significance and appeared to be applicable after neoadjuvant chemotherapy, as well as in medically untreated tumours. These indices may offer a useful practical value to evaluate the residual disease, and subsequently to identify subgroups of patients with a better prognosis. For these patients, it might be possible to avoid adjuvant treatment in order to improve the quality of life.

\section{REFERENCES}

Adjuvant Therapy for Breast Cancer (2000) NIH consensus statement. 17(4): $1-35$

Amat S, Penault-Llorca F, Cure H, Le Bouedec G, Achard JL, Van Praagh I, Feillel V, Mouret-Reynier MA, Dauplat J, Chollet P (2002) ScarffBloom - Richardson (SBR) grading: a pleiotropic marker of chemosensitivity in invasive ductal breast carcinomas treated by neoadjuvant chemotherapy. Int J Oncol 20: 791-796

Balslev I, Axelsson CK, Zedeler K, Rasmussen BB, Carstensen B, Mouridsen HT (1994) The Nottingham prognostic index applied to 9,149 patients from the studies of the Danish breast Cancer Cooperative Group (DBCG). Breast Cancer Res Treat 32: 281-290

Belembaogo E, Feillel V, Chollet P, Cure H, Verrelle P, Kwiatkowski F, Achard JL, Le Bouëdec G, Chassagne J, Bignon Y-J, de Latour M, Lafaye C, Dauplat J (1992) Neoadjuvant chemotherapy in 126 operable breast cancers. Eur J Cancer 28A(4/5): 896-900

Cameron DA, Anderson ED, Levack P, Hawkins RA, Anderson TJ, Leonard RC, Forrest AP, Chetty U (1997) Primary systemic therapy for operable breast cancer - 10-year survival data after chemotherapy and hormone therapy. Br J Cancer 76: 1099-1105

Charpin C, Bacquie N, Bouvier C, Devictor B, Boulat J, Andrac L, Lavaut MN, Allasia C, Piana L (1995) Comparison of the prognostic significance of current and modified histological grades in breast carcinomas. Anticancer Res 15(6B): 2611-2617

Chollet P, Amat S, Cure H, de Latour M, Le Bouedec G, Mouret-Reynier MA, Ferriere JP, Achard JL, Dauplat J, Penault-Llorca F (2002) Prognostic significance of a complete pathological response after induction chemotherapy in operable breast cancer. Br J Cancer 86(7): 1041 - 1046

Chollet P, Amat S, Penault-Llorca F, Fetissol F, Body G, Mouret-Reynier MA, Bons JM, Cure H, Dauplat J, Baugnoux P, (2000) High pathological response rate induced by primary docetaxel monotherapy in operable breast cancer. Breast Cancer Res Treat 64: 67 [abstract no. 251]

Chollet P, Charrier S, Brain E, Cure H, Van Praagh I, Feillel V, de Latour M, Dauplat J, Misset JL, Ferriere JP (1997) Clinical and pathological response to primary chemotherapy in operable breast cancer. Eur $J$ Cancer 33: $862-866$

Cox DR (1972) Regression models and life tables. JR Stat Soc B 34: $187-202$

Cure H, Amat S, Peault-Llorca F, Le Bouëdec G, Ferriere JP, MouretReynier MA, Kwiatkowski F, Feillel V, Dauplat J, Chollet P (2002) Prognostic value of residual node involvement in operable breast cancer after chemotherpy. Breast Cancer Res Treat 76(1): 37-45

D’Eredita G, Giardina C, Martellotta M, Natale T, Ferrarese F (2001) Prognostic factors in breast cancer: the predictive value of the Nottingham Prognostic Index in patients with a long-term follow-up that were treated in a single institution. Eur J Cancer 37(5): 591-596

Fisher B, Bryant J, Wolmark N, Mamounas E, Brown A, Fisher ER, Wickerham DL, Begovic M, DeCillis A, Robidoux A, Margolese RG, Cruz Jr AB, Hoehn JL, Lees AW, Dimitrov NV, Bear HD (1998) Effect of preoperative chemotherapy on the outcome of women with operable breast cancer. J Clin Oncol 16: 2672-2685

Fredriksson I, Liljegren G, Arnesson L, Emdin S, Palm-Sjovall M, Fornander T, Holmqvist M, Holmberg L, Frisell J (2002) Local recurrence in the breast after conservative surgery - a study of prognosis and prognostic factors in 391 women. Eur J Cancer 38(14): 1860-1870
Galea MH, Blamey RW, Elston CE, Ellis IO (1992) The Nottingham prognostic index in primary breast cancer. Breast Cancer Res Treat 22: $207-219$

Haybittle JL, Blamey RW, Elston CW, Johnson J, Doyle PJ, Campbell FC, Nicholson RI, Griffiths K (1982) A prognostic index in primary breast cancer. Br J Cancer 45: 361 - 366

Kaplan EL, Meier P (1958) Nonparametric estimation from incomplete observations. Clinical course of breast cancer. J Am Stat assoc 185: $1457-1481$

Kuerer HM, Newman LA, Smith TL, Ames FC, Hunt KK, Dhingra K, Theriault RL, Singh G, Binkley SM, Sneige N, Buchholz TA, Ross MI, McNeese MD, Buzdar AU, Hortobagyi GN, Singletary SE (1999) Clinical course of breast cancer patients with complete pathologic primary tumour and axillary lymph node response to doxorubicin-based neoadjuvant chemotherapy. J Clin Oncol 17(2): 460-469

Latinovic L, Heinze G, Birner P, Samonigg H, Hausmaninger H, Kubista E, Kwasny W, Gnant M, Jakesz R, Oberhuber G, The Austrian Breast and Colorectal Cancer Study Group (2001) Prognostic relevance of three histological grading methods in breast cancer. Int J Oncol 19(6): $1271-1277$

Le Doussal V, Tubiana-Hulin M, Friedman S, Hacene K, Spyratos F, Brunet M (1989) Prognostic value of histologic grade nuclear components of Scarff-Bloom-Richardson (SBR). An improved score modification based on a multivariate analysis of 1262 invasive ductal breast carcinomas. Cancer 64(9): 1914-1921

Machiavelli MR, Romero AO, Perez JE, Lacava JA, Dominguez ME, Rodriguez ME, Barbieri MR, Romero Acuna LA, Romero Acuna JM, Langhi MJ, Amato S, Ortiz EH, Vallejo CT, Leone BA (1998) Prognostic significance of pathological response of primary tumour and metastatic axillary lymph nodes after neoadjuvant chemotherapy for locally advanced breast carcinoma. Cancer J Sci Am 4(2): $125-131$

Makris A, Powles TJ, Allred DC, Ashley SE, Trott PA, Ormerod MG, Titley JC, Dowsett M (1999) Quantitative changes in cytological molecular markers during primary medical treatment of breast cancer: a pilot study. Breast Cancer Res Treat 53(1): 51 - 59

Malmstrom P, Bendahl PO, Boiesen P, Brunner N, Idvall I, Ferno M, South Sweden Breast Cancer Group (2001) S-phase fraction and urokinase plasminogen activator are better markers for distant recurrences than Nottingham Prognostic Index and histologic grade in a prospective study of premenopausal lymph node-negative breast cancer. J Clin Oncol 19(7): $2010-2019$

Mantel N (1966) Evaluation of survival data and two row rank order statistics arising in its consideration. Cancer Chemother Rep 50(3): $163-170$

Page DL (1991) Prognosis and breast cancer. Recognition of lethal and favorable prognostic types. Am J Surg Pathol 15(4): 334-349

Pierga JY, Mouret E, Dieras V, Laurence V, Beuzeboc P, Dorval T, Palangie T, Jouve M, Vincent-Salomon A, Scholl S, Extra JM, Asselain B, Pouillart $P$ (2000) Prognostic value of persistent node involvement after neoadjuvant chemotherapy in patient with operable breast cancer. Br J Cancer 83(11): 1480-1487

Sauerbrei W, Hubner K, Schmoor C, Schumacher M (1997) Validation of existing and development of new prognostic classification schemes in node negative breast cancer. German Breast Cancer Study Group. Breast Cancer Res Treat 42(2): 149-163 
Simpson JF, Gray R, Dressler LG, Cobau CD, Falkson CI, Gilchrist KW, Pandya KJ, Page DL, Robert NJ (2000) Prognostic value of histologic grade and proliferative activity in axillary node-positive breast cancer: results from the Eastern Cooperative Oncology Group Companion Study, EST 4189. J Clin Oncol 18(10): 2059-2069

Sobin LH, Wittekind CH (1997) UICC - TNM Classification of Malignant Tumours, 5th edn. New York: Wiley-Liss

Sundquist M, Thorstenson S, Brudin L, Nordenskjold B (1999) Applying the Nottingham Prognostic Index to a Swedish breast cancer population. South East Swedish Breast Cancer Study Group. Breast Cancer Res Treat 53(1): $1-8$
Van Praagh I, Amat S, Delva R, Leduc B, Mouret-Reynier MA, Lortholary A, Sillet-Bach I, Fleury J, Bonnel C, Feillel V, Penault-Llorca F, Le Bouedec G, Chollet P (2001) Induction chemotherapy in operable breast cancer by NET regimen: multicentric phase II trial (Meeting abstract). Proc ASCO 20: 35b [abstract no. 1889]

Van Praagh I, Charrier S, Leduc B, Curé H, Le Bouëdec G, Achard J.L, Ferrière J.P, Feillel V, De Latour Monique, Dauplat J, Chollet P (2002) Efficacy of a primary chemotherapy regimen combining vinorelbine, epirubicin and methotrexate (VEM) as neoadjuvant treatment in 89 patients with operable breast cancer. Oncologist 7(5): $418-423$ 